\title{
Matteo Ragni
}

Nato a Milano nel 1972. Si è laureato in Architettura al Politecnico di Milano. Dal 1994 progetta e si occupa di design negli ambiti più diversi dell'industria e dell'artigianato, con un interesse che si focalizza sempre di più sulla progettazione volta ad unire funzione e innovazione tipologica. Ha lavorato per molte aziende, per le quali ha spesso integrato all'attività di designer quella di creative director, dando vita a sistemi di comunicazione e produzione perfettamente sincronici. É stato uno dei più giovani vincitori del Compasso d'Oro a 29 anni, nel 2001, con la posata usa e getta Moscardino, disegnata insieme a Giulio lacchetti. Nel 2014 riceve il secondo Compasso d'Oro, sempre con Giulio lacchetti, per il design di una serie di tombini per Montini.

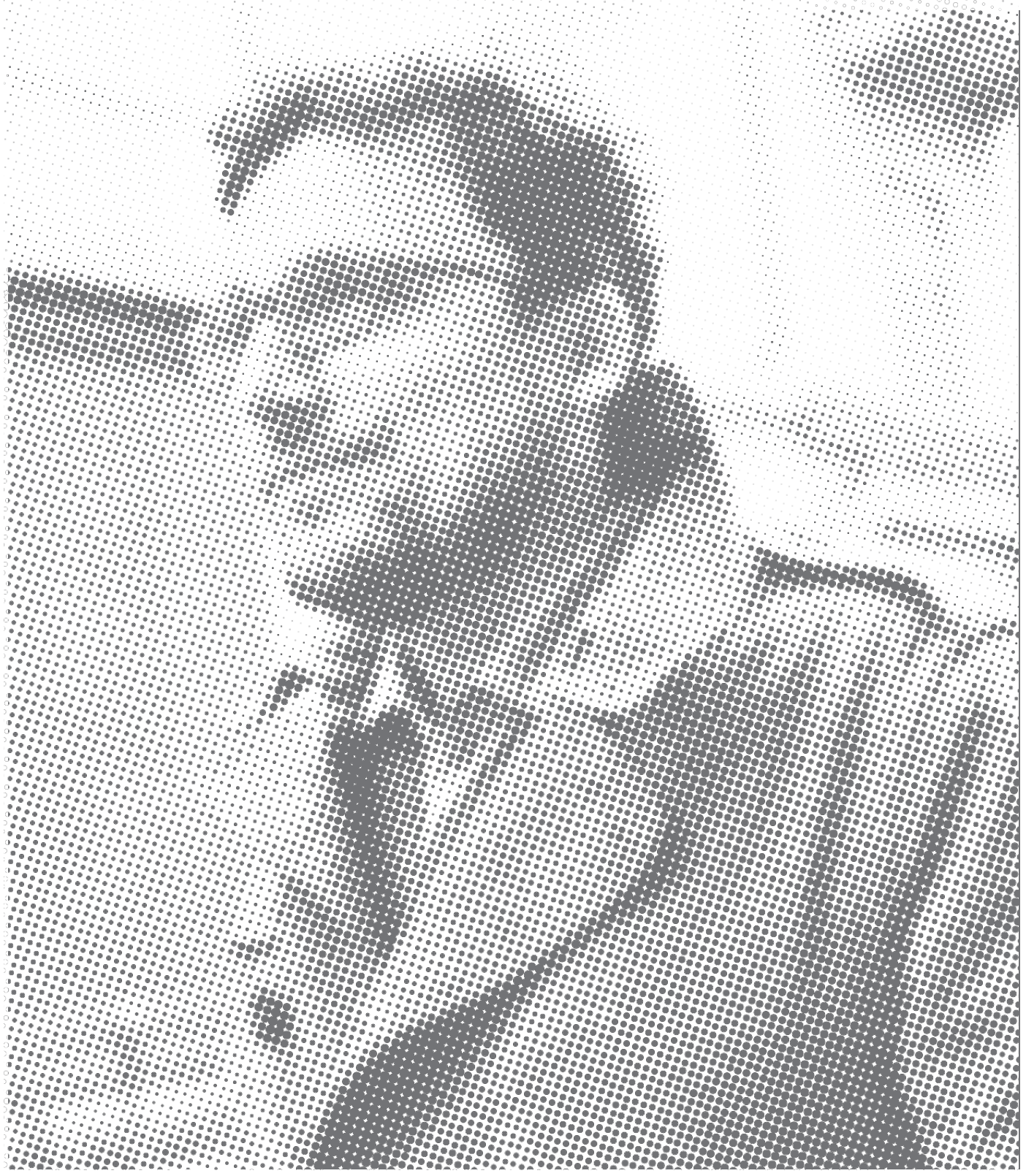




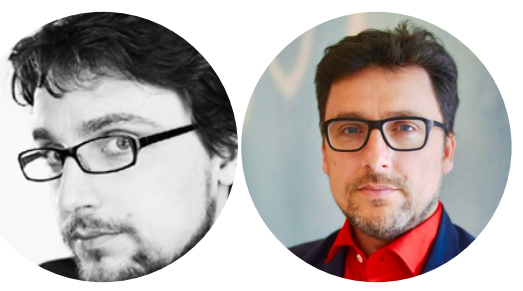

Matteo Ragni | info@matteoragni.com

"il design è per me un atto eroico di poesia solida, frutto di un pensiero leggero e sofisticato che deriva dal"attitudine al cambiamento della società in cui viviamo. La capacità di indagare le esigenze contemporanee di un mercato in continua evoluzione è la chiave di un progetto buono e giusto.

Bruno Munari

Ho conosciuto Carmelo quando, nel 1997, ricevetti l'incarico di coordiantore didattico nella meravigliosa sede cagliaritana dello IED. lo, 25enne laureando tardivo in architettura e o mista designer autodidatta, la presi come una missione speciale e giurai a me stesso che quella esperienza avrebbe cambiato la mia vita, avvicinandomi d'un fiato al magico mondo del design. Dopo poco meno di un anno, di ritorno a Milano, ritrovai Carmelo nel suo "habitat" naturale, ovvero al Cried, dove era direttore oltre che fondatore. Mi propose un'altra sfida: coordinare il master in design e bionica. A quei tempi la mia cultura in merito al design bionico si limitava purtroppo solamente alla nota serie televisiva della donna bionica, ma mi misi subito ad assorbire come una spugna da lui tutto quello che poteva essermi di aiuto per esplorare quel misterioso e magico mondo. Nella mia vita rofessionale ho sempre avuto la fortuna di incontrare persone eccezionali e ottimi maestri, leali e generosi con me come lo è stato Carmelo. Un maestro non accademico, ma una persona che, con il suo fare, mi ha dimostrato che se si coltiva una passione per qualcosa, tutto diventa possibile e i sogni diventano realtà. Nei due anni passati al Cried ho imparato che la Natura è la migliore designer di sempre e che anche la belllezza può essere funzionale. Ma la lezione più importante è stata quella di capire che "less is more", il mantra di Mies van der Rohe che avevo imparato a recitare al Politecnico, altro non era che una pratica comune della Natura per costruire sistemi per la sopravvivenza della specie animale e vegetale. Così la mia atitudine al progetto si è plasmata grazie a queste lezioni "botaniche", oltre che allo studio dei maestri del nostro bel design italiano.

Uno dei miei primi progetti è stato, ironia della sorte, un porta uovo, oggetto tendenzialmente inutile ma ideato per sfidare la gravità con un semplice foglio di polipropilene fustellato. Una sorta di elogio alla tensione strutturale, figlio di una frase in la no che io, pessimo studente di statica e scienza delle costruzioni, avevo letto in un libro: "sic tensio ut vis" (che tradotto dal latino significa "dove c'è tensione c'è forza"). Così un semplice foglio è diventato uno strumento meccanico per sorreggere il peso di un uovo, "forma perfetta benchè fatta col culo" (cit. Bruno Munari). Negli anni ho intrapreso la mia professione di designer esplorando ben altre tipologie di prodotto, dai tombini stradali in ghisa alleggerita agli occhiali in legno e alluminio, cercando sempre di fare tesoro di quella meraviglia nel ricercare forme leggere che potessero rispondere al requisito "do more with less". Grazie Carmelo, quello che sono oggi come designer lo devo anche a te, alla tua capacità di stupirti e di stupire davanti a una foglia o a un seme che porta dentro di sé il gene del futuro.
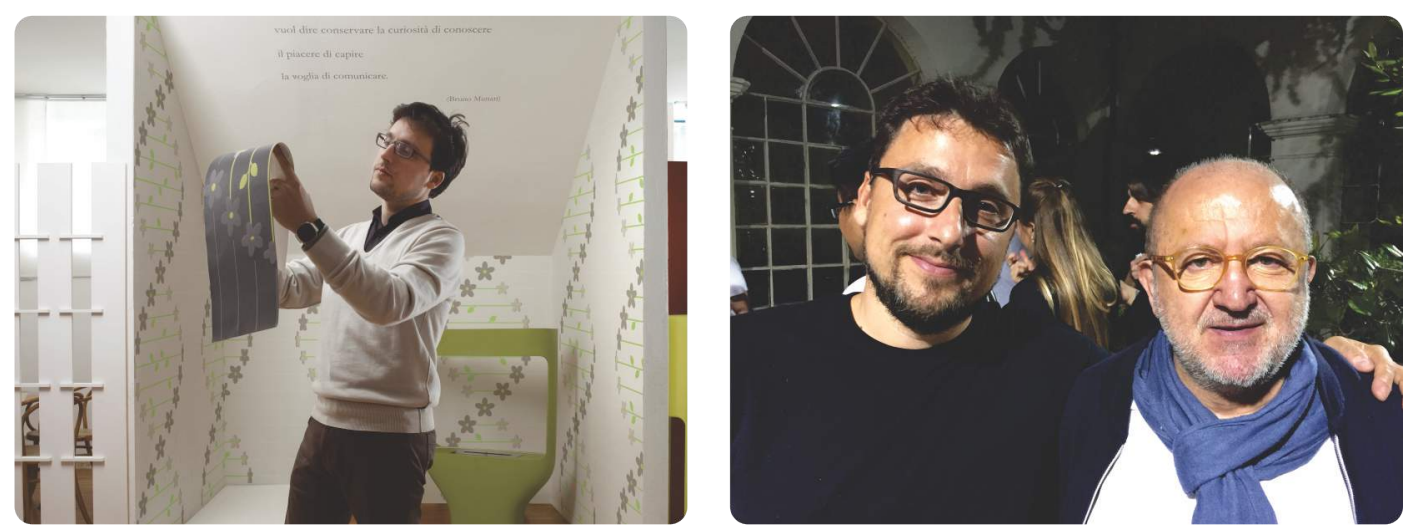


\section{[MOSCARDINO]}
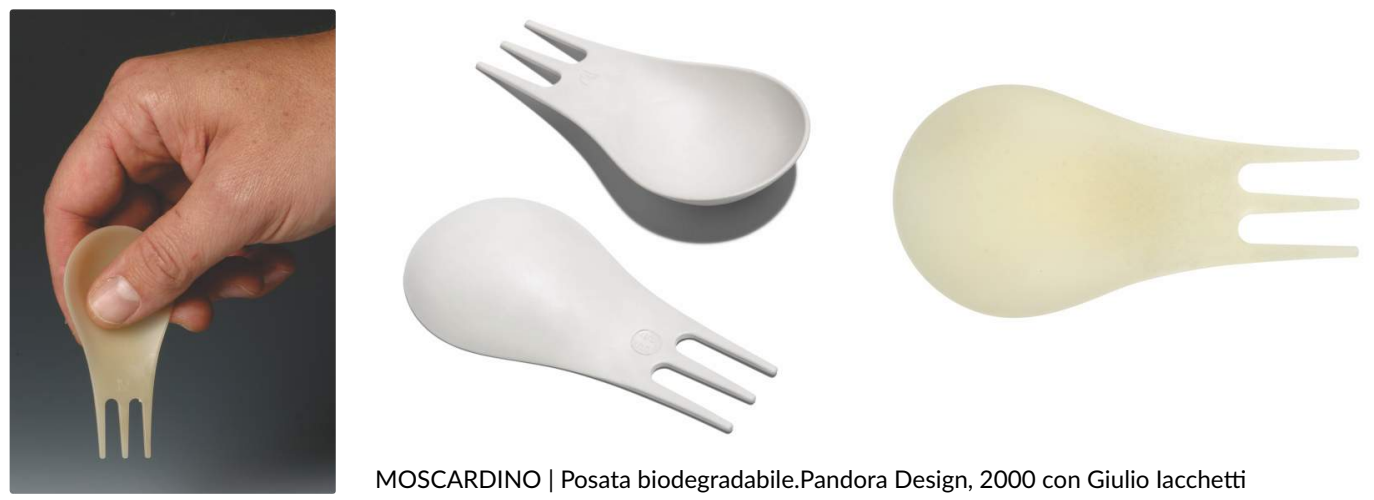

MOSCARDINO | Posata biodegradabile.Pandora Design, 2000 con Giulio lacchetti
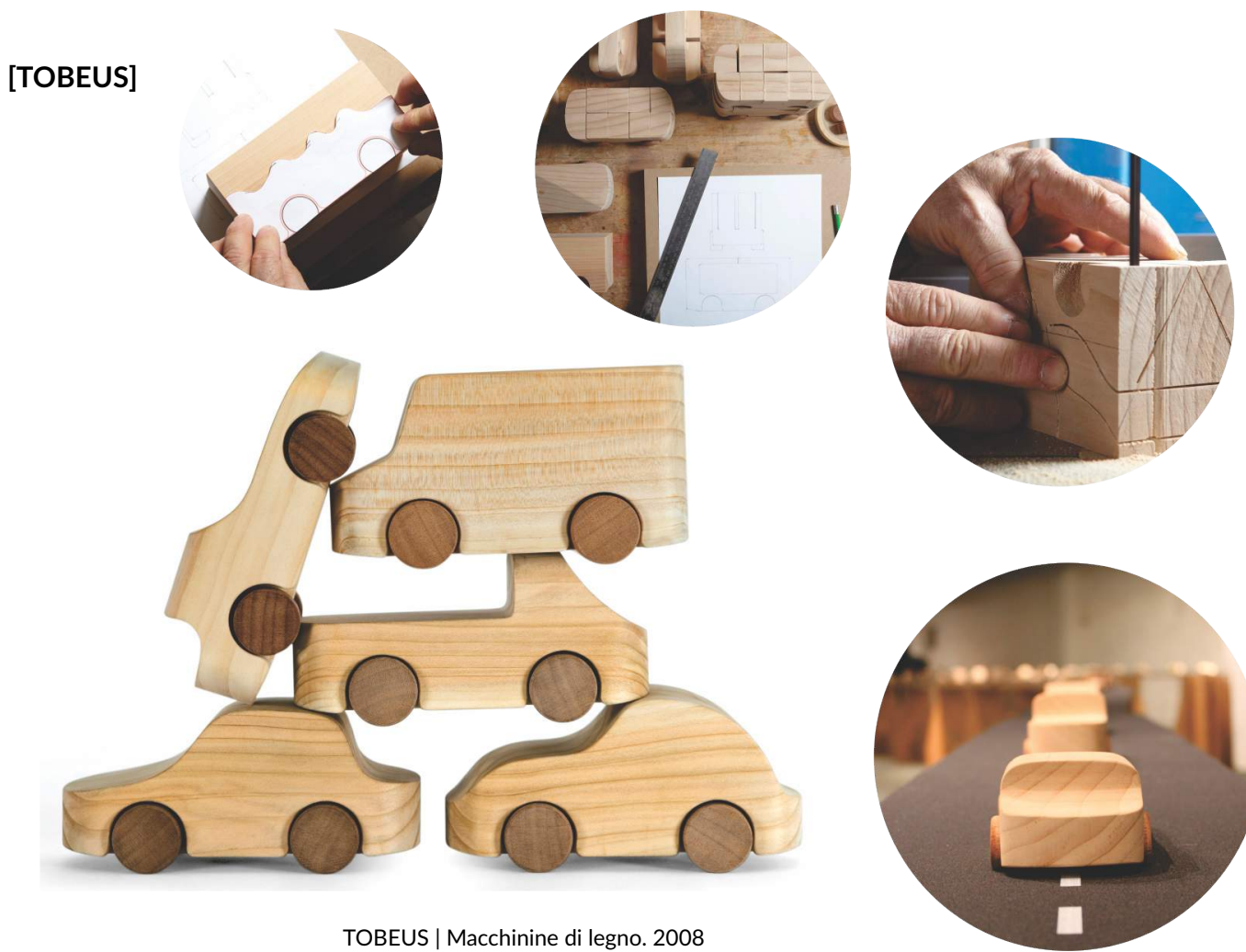

[TOMBINI MONTINI]
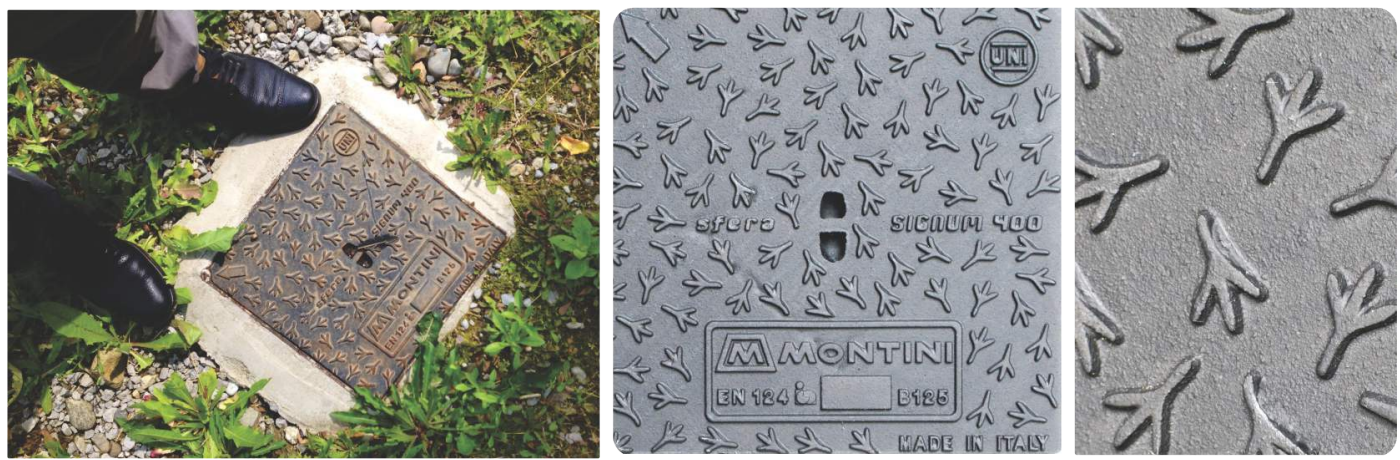

TOMBINI | Serie di tombini e caditoie in ghisa sferoidale

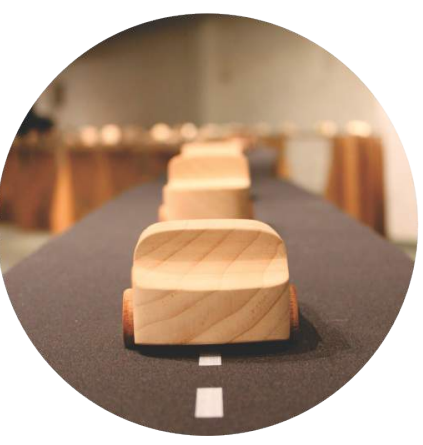




\section{[UNOALD]}
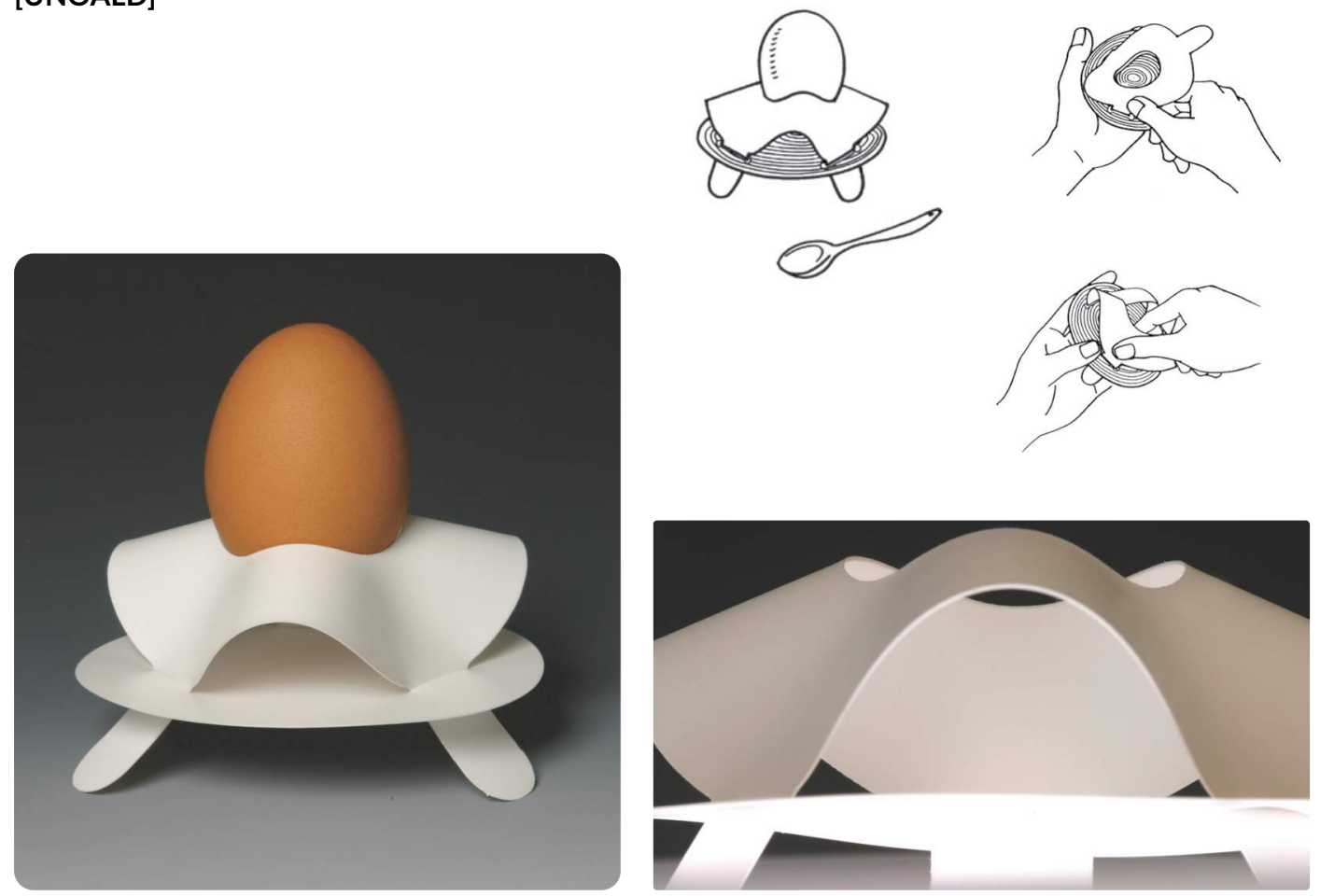

\section{[W-EYE]}

\section{UNOALDì | Porta uovo da viaggio. Progetti srl, 1996}
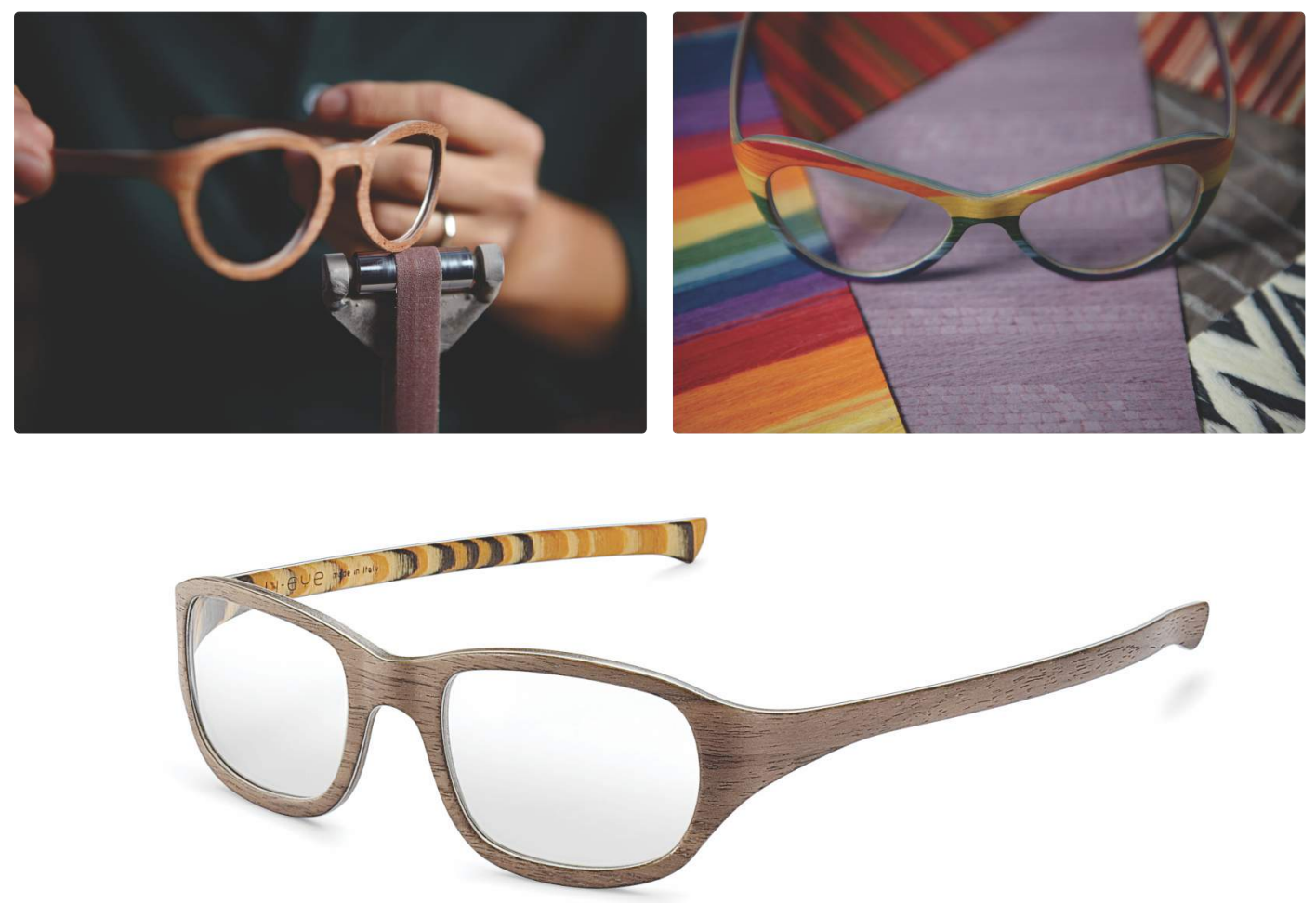

W-EYE | Occhiali in legno e alluminio. 2009 


\section{[PROGETTO HUB PER FANTONI]}

struttura ossea svuotata che può essere arredata a piacere con piccole pareti mobili.
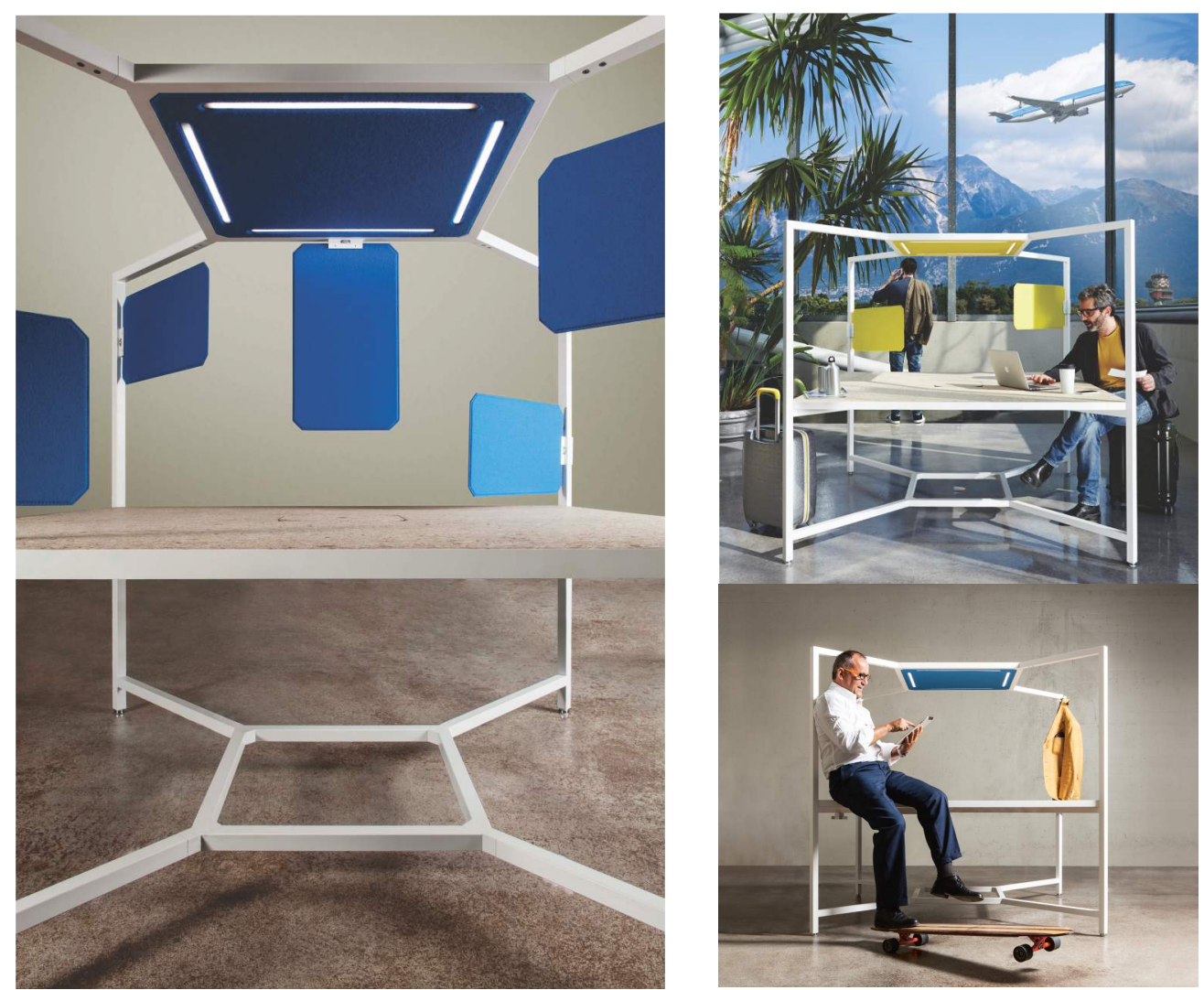

HUB | Sistema operativo e cooperativo per ufficio contemporaneo. Fantoni, 2014

\section{[PROGETTO POLTRONCINA C-VRON PER CITROEN]}
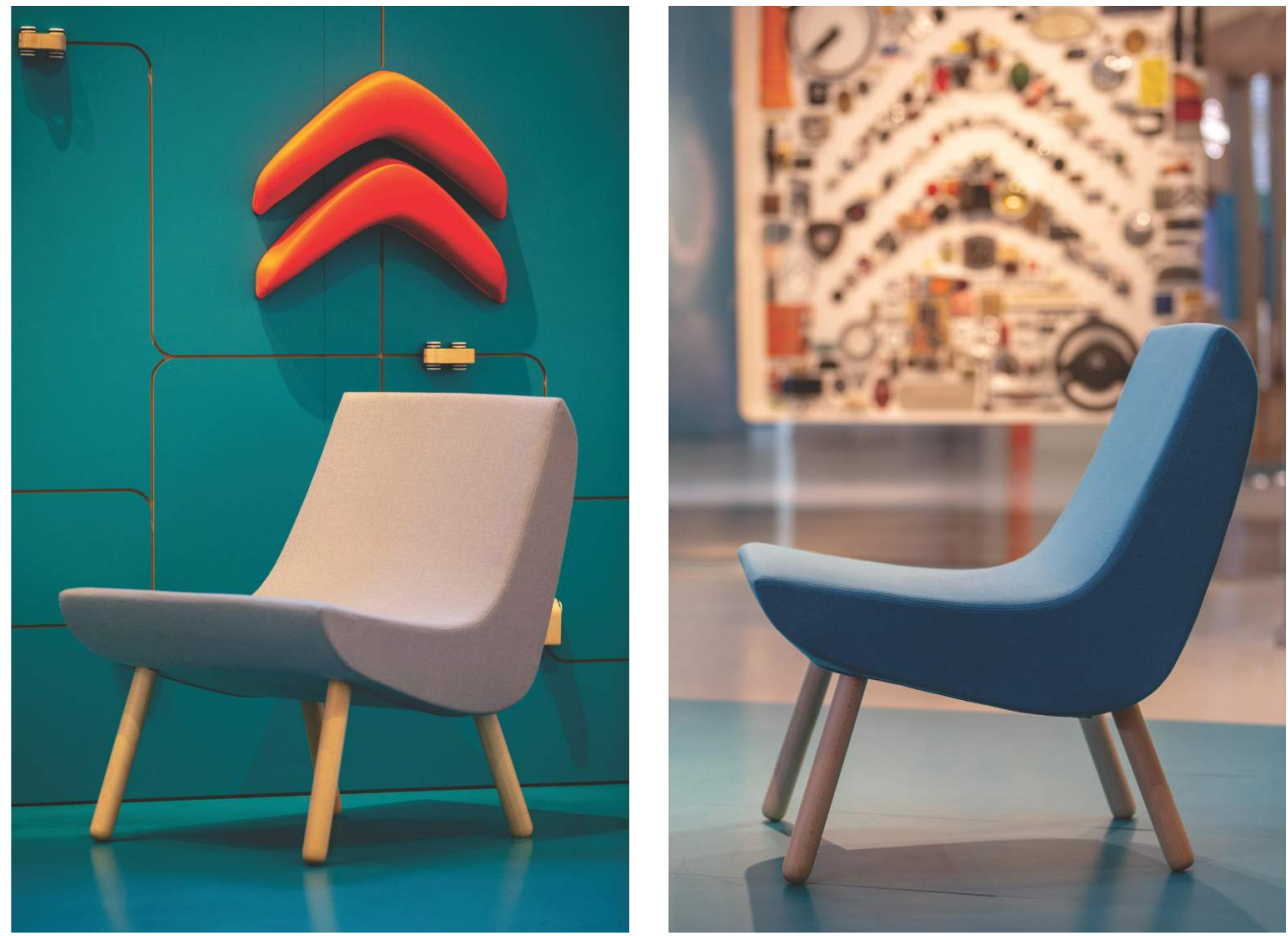

C-VRON | Poltrona. Citroën con Very Wood, 2019 

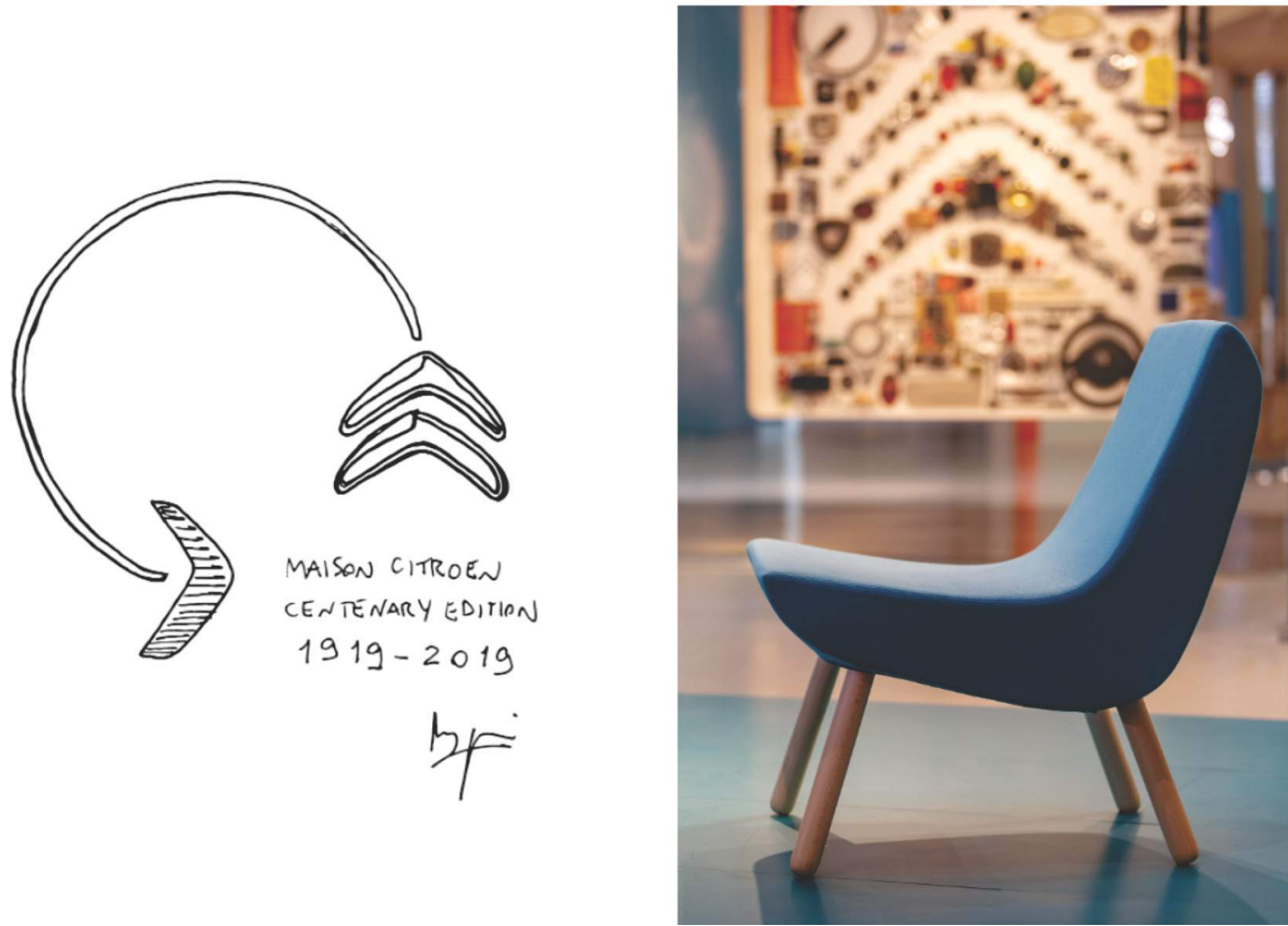

MAISON CITROEN

CENTENARY EDITION

$1919-2019$

年

UNOALDì | Porta uovo da viaggio. Progetti srl, 1996

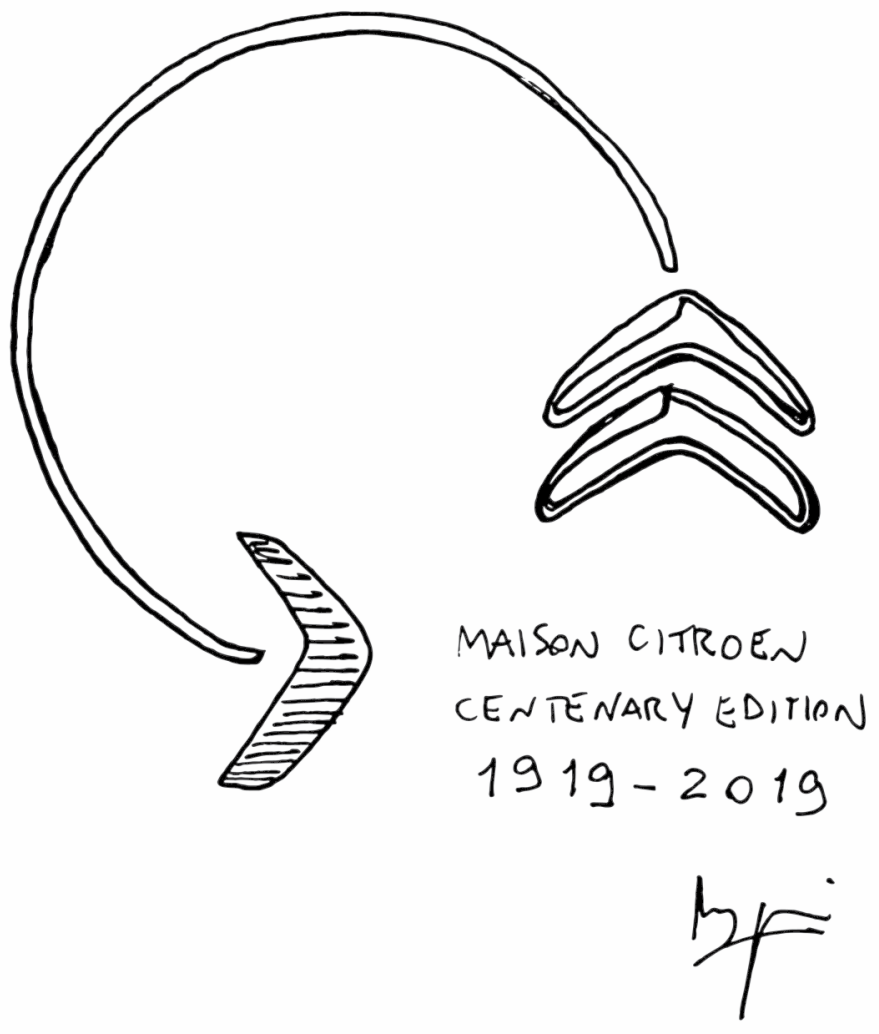

